\title{
Testiculaire sperma-extractie (TESE): een update
}

\author{
Marij Dinkelman-Smit ${ }^{1}$
}

Published online: 5 November 2018

(c) The Author(s) 2018

\section{Samenvatting}

Dit artikel geeft een overzicht van de historie van TESE en TESE-ICSI, de Nederlandse context, de fysiologie/pathofysiologie en histologie van het ziektebeeld niet-obstructieve azoöspermie (NOA) en de uitkomst van ICSI met testiculaire zaadcellen. Ook worden de operatietechniek en de work-up van TESE besproken, en de mogelijke complicaties, langetermijngevolgen en controversiële voorbehandelingen. Tot slot komen innovatieve ontwikkelingen op het gebied van diagnostiek en behandeling aan bod.

Trefwoorden testiculaire sperma-extractie $\cdot$ TESE $\cdot$ TESE-ICSI $\cdot$ niet-obstructieve azoöspermie $\cdot$ niet-obstructieve azoöspermie (NOA)

\section{Testicular sperm extraction (TESE): an update}

\begin{abstract}
This article gives an overview of the history of TESE and TESE-ICSI, the Dutch context, physiology, pathophysiology and histology of the phenotype non obstructive azoospermia. Outcome of ICSI with testicular sperm is discussed. As well as work-up for TESE, surgical technique, complications, late effects and controversial pretreatment strategies. Finally, innovations in diagnostics and treatment are discussed.
\end{abstract}

Keywords testicular sperm extraction $\cdot$ TESE $\cdot$ TESE-ICSI $\cdot$ non-obstructive azoospermia $\cdot$ NOA

\section{Introductie}

Een op de zes paren in Nederland krijgt te maken met uitblijven van spontane zwangerschap na één jaar op conceptie gerichte coïtus. Na analyse blijkt bij $10 \%$ van de mannen sprake te zijn van een azoöspermie [1]. Met urologisch vakmanschap kan spontane zwangerschap bij patiënten met iatrogene en postinfectieuze obstructieve azoöspermie (OA) alsnog mogelijk gemaakt worden door middel van microchirurgische vaso-epididymostomie [2]. Als microscopische reconstructie technisch niet mogelijk is doordat de obstructie distaal van de epididymis gelegen is, kan kinderwens bij OA behandeld worden met intracytoplasmatische sperma-injectie (ICSI) in combinatie met chirurgisch

Marij Dinkelman-Smit, MD PhD FEBU FECSM

m.smit.3@erasmusmc.nl

1 Erasmus MC, Universitair medisch centrum, Rotterdam, Nederland verkregen zaadcellen uit de gedilateerde epididymis. Dit kan zowel percutaan (PESA) als microchirurgisch (MESA) worden uitgevoerd, met goede zwangerschapsresultaten [3].

Bij het merendeel van de patiënten die zich presenteren met afwezigheid van zaadcellen in het ejaculaat is er echter sprake van niet-obstructieve azoöspermie (NOA). NOA komt voor bij ongeveer $1 \%$ van de algemene bevolking [4]. De oorzaak van NOA is ernstig gestoorde of afwezige spermatogenese en kan zowel aangeboren, verworven als idiopathisch van oorzaak zijn [4]. Testiculaire sperma-extractie (TESE) is de voorkeursbehandeling om bij mannen met NOA biologisch vaderschap toch mogelijk te maken.

Dit artikel geeft een overzicht van de historie van TESE en TESE-ICSI, de Nederlandse context, de fysiologie/ pathofysiologie en histologie van het ziektebeeld NOA en de uitkomst van ICSI met testiculaire zaadcellen. De operatietechniek en de work-up van TESE, alsook mogelijke complicaties en langetermijngevolgen en controversiële voorbehandelingen, worden besproken. Tot slot komen 
ontwikkelingen in innovatie van diagnostiek en behandeling aan bod.

\section{Historie}

De eerste publicatie over succesvolle fertilisatie met behulp van testiculaire zaadcellen dateert uit 1993 [5]. Dichter bij huis publiceerden Paul deVroey en Herman Tournaye, gynaecologen aan de Vrije Universiteit van Brussel en Sherman Silber, uroloog in St Lukes Hospital uit St Louis, Missouri in 1994 over de TESE-ICSI-resultaten van drie mannen met obstructieve azoöspermie [6]. Aangezien er bij scrotale exploratie bij deze patiënten geen zaadcellen in de epididymis en rete testis werden gevonden, werd een testiculair biopt afgenomen waaruit testiculaire zaadcellen werden geïsoleerd, die vervolgens vers geïnjecteerd werden in oöcyten. In de jaren daarna is gewerkt aan verfijning van zowel de operatietechniek als de zaadcelextractie en opwerktechniek op het IVF-lab om TESE en TESE-ICSI in te kunnen zetten als behandeling van kinderwens bij mannen met ernstig gestoorde spermatogenese.

\section{Nederlandse context}

In 1998 werd een moratorium opgelegd op geassisteerde voortplanting met chirurgisch verkregen zaadcellen in $\mathrm{Ne}$ derland, totdat de veiligheid van de behandeling voor het nageslacht voldoende bewezen werd. Nederland werd het enige land ter wereld dat beperkingen oplegde aan TESEICSI. Aan voortplantingscentra van het Radboudumc en het AMC (nu: Amsterdam UMC, locatie AMC) werd vanaf 2007 in studieverband TESE-ICSI uitgevoerd in het kader van het onderzoeksprotocol 'ICSI met testiculaire zaadcellen bij mannen met azoöspermie: een observationeel onderzoek met follow-up van kinderen'. Veel patiënten met NOA weken uit naar België en Duitsland voor TESE- en TESEICSI-behandelingen. In het ErasmusMC vond vanaf 2007 TESE plaats, waarna gecryopreserveerde testiculaire zaadcellen getransporteerd werden naar Brussel of Gent voor TESE-ICSI-behandeling daar, na opstarten van de ICSIprocedure in het Maasstad Ziekenhuis.

De Nederlandse observationele studie toonde geen significant verschil aan in aangeboren afwijkingen bij 197 kinderen die waren geboren uit ICSI met testiculaire zaadcellen in vergelijking tot kinderen die waren geboren uit ICSI met ejaculatoire zaadcellen. Bij 6,6\% van de kinderen die waren geboren na TESE-ICSI werd een grote aangeboren afwijking geconstateerd, bij 11,5\% een kleine aangeboren afwijking. Een systematische review uit 2010 bevestigde dat TESE-ICSI niet geassocieerd is met een verhoogd risico op congenitale afwijkingen bij het nageslacht. Percen- tages grote congenitale afwijkingen waren $4,6 \%$ na TESEICSI, versus $4,4 \%$ na ICSI met niet-chirurgisch verkregen zaadcellen [7].

Medio 2013 publiceerden de Nederlandse Vereniging voor Obstetrie en Gynaecologie (NVOG), de Nederlandse Vereniging voor Urologie (NVU) en de Vereniging voor klinische embryologie (KLEM) de kwaliteitsnorm 'Geassisteerde voortplanting met chirurgisch verkregen zaadcellen' [8] In dit document presenteren zij de voorwaarden en kwalificaties waaraan een IVF-centrum, het IVF-laboratorium en de betrokken medisch specialisten geacht worden te voldoen. De instelling die TESE en TESE-ICSI uitvoert dient onder meer over een ISO-15189 of CCKL-certificering en een uroloog-androloog te beschikken. Het minimale volume per IVF-centrum is gesteld op 100 TESE- en 100 TESE-ICSI-behandelingen per jaar.

In 2014 werd het moratorium opgeheven, nadat een tweejaarlijks 'TESE-NL'-overleg tussen TESE-ICSI-centra in Nederland in het leven werd geroepen. Sinds 2017 heeft de multidisciplinaire 'SIG Andrologie' de functie van het TESE-NL-overleg overgenomen. Tijdens tweejaarlijkse bijeenkomsten worden aantallen TESE's en TESE-ICSI's, uitkomsten en complicaties per TESE-ICSI-centrum en de samenwerking in wetenschappelijke projecten besproken. In het SIG-bestuur zitten urologen-andrologen, die ook deel uitmaken van de werkgroep Andrologie van de NVU. Lidmaatschap van de SIG Andrologie en toegang tot de vergaderingen is multidisciplinair; de jaarlijkse contributie bedraagt 25 euro. Lidmaatschap van de SIG 'Andrologie binnen de VPG' kan worden aangevraagd via liesbethekkers @ nvog.nl, onder vermelding van NAW-gegevens en BIGregistratie.

\section{Fysiologie spermatogenese}

Bij normale testisfunctie worden dagelijks miljoenen zaadcellen geproduceerd die worden afgegeven aan het lumen in de tubuli seminiferi en onder lage druk doorstromen naar de rete testis en de epididymis. In de epididymis rijpen de zaadcellen verder uit en verkrijgen ze de capaciteit om de oöcyt op eigen kracht te bereiken en te bevruchten.

Normale spermatogenesehistologie wordt gekenmerkt door aanwezigheid van alle uitrijpingsfasen van germinale cellen; van differentiatie van de spermatogoniale stamcel, tot spermatocyt, spermatide en spermatozoa.

\section{Uitkomst van ICSI met testiculaire zaadcellen}

Testiculaire zaadcellen hebben geen of minimale motiliteit, en het acrosoom, dat voor de fusie van de zaadcelkern met de eicelwand zorgt, is niet ontwikkeld. Testiculaire zaad- 
cellen worden ook wel 'onrijp' genoemd. Feitelijk is het zaadcel-DNA intact en heeft het bevruchtend vermogen, mits het bij de kern van de oöcyt gebracht wordt. Na injectie van een vitale testiculaire zaadcel in de oöcyt is de kans op een gezond embryo per ICSI-cyclus echter lager bij NOA dan bij OA, en ook lager dan bij ICSI met zaadcellen in het ejaculaat [9].

Bij de counseling van paren bij wie de man verdacht wordt van NOA, is de studie van Vloeberghs et al. illustratief: de kans op een genetisch eigen kind van mannen met NOA die nog een TESE moeten ondergaan is 1:7 [10]. De kans op het vinden van zaadcellen bij TESE bij NOA is ongeveer $50 \%$. Predictiemodellen kunnen dit percentage verfijnen [11]. Na succesvolle TESE zijn zwangerschapspercentages per TESE-ICSI-cyclus $15 \%$ bij mannen met NOA en $28 \%$ bij mannen met $\mathrm{OA}$ in een retrospectieve studie onder 595 paren [12].

De belangrijkste verklaring voor de lagere fertilisatie en het ontwikkelingspotentieel van het embryo na TESE-ICSI bij NOA is de ernst van de zaadcelfactor. Bij OA is de spermatogenese feitelijk ongestoord en is genetische diagnostiek normaal. In geval van NOA is er - behalve een verminderd aantal beschikbare zaadcellen voor injectie sprake van gecompliceerde selectie van vitale zaadcellen doordat bij NOA zaadcelmotiliteit zwak is of ontbreekt. Injectie van zwak-motiele zaadcellen en selectietechnieken als tail touch om vitale immotiele zaadcellen van niet-vitale immotiele zaadcellen te onderscheiden, verhogen het percentage fertilisaties per geïnjecteerde testiculaire zaadcel [13].

\section{Pathofysiologie NOA}

Bij NOA is het aantal tubuli waarin spermatogenese plaatsvindt sterk gereduceerd of het proces van spermatogenese inadequaat, waardoor er geen of minimaal transport van testiculaire zaadcellen naar de epididymis plaatsvindt. In het continuüm van intacte tot afwezige spermatogenese zitten mengvormen, waarbij er in het ene ejaculaat wel enkele zaadcellen aantoonbaar kunnen zijn, en in het volgende ejaculaat niet. Wanneer er minder dan 1 miljoen zaadcellen per milliliter gevonden worden, spreekt men van cryptozoöspermie. Cryptozoöspermie en absolute azoöspermie kunnen afwisselend voorkomen bij $20 \%$ van de mannen met NOA.

De meest voorkomende oorzaken van NOA zijn testiculair falen zonder aanwijsbare oorzaak en testiculaire dysgenesie: een ontwikkelingsstoornis van de testis die wordt gekenmerkt door cryptorchisme en orchidopexie op kinderleeftijd (Tab. 1) [14]. Meestal betreft het bilaterale testiculaire dysgenesie, maar ook unilateraal cryptorchisme en ascensus testis kunnen geassocieerd zijn met NOA [15].
Tabel 1 Oorzaken van NOA op basis van testiculair falen

varicocele

postchemotherapie

hypogonadisme: ten gevolge van anabolenmisbruik, secundair hypogonadisme (Kallmann-syndroom, idiopathisch hypogonadotroop hypogonadisme)

genetisch: Klinefelter-syndroom, AZF-microdeleties van het Y-chromosoom

testiculaire dysgenesie

e causa ignota

Testiculair falen kan ook voorkomen bij varicocele, postchemotherapie en hypogonadisme.

Genetische oorzaken van NOA zijn seksegerelateerde chromosomale variaties, zoals het Klinefelter-syndroom (47 XXY) (zie [16]) en azoöspermiefactor (AZF) microdeleties op het Y-chromosoom.

Deze aandoeningen worden gevonden bij $8-12 \%$ van de mannen die in analyse zijn voor NOA. De meest voorkomende AZF-deleties zijn AZFc-deleties (65-70\%), gevolgd door $\mathrm{AZFb}$ - en $\mathrm{AZFb}+\mathrm{c}-$ of $\mathrm{AZFa}+\mathrm{b}+\mathrm{c}$-deleties (25-30\%) en AZFa-deleties (5\%). TESE wordt afgeraden bij het vaststellen van AZFb- en AZFa-deleties, aangezien de kans op het vinden van bruikbare zaadcellen nihil is [17]. Mannen met een AZFc-deletie moeten worden gecounseld over NOA bij mannelijk nageslacht na succesvolle TESEICSI-behandeling.

Aangezien AZF-microdeleties zeer zeldzaam zijn bij spermaconcentraties $>1$ miljoen/ml, wordt in de praktijk deze grens voor genetische diagnostiek gehanteerd [18]. Richtlijnen van de EAU en EAA schrijven - nog - een grens voor van een concentratie $<5$ miljoen zaadcellen per $\mathrm{ml}$.

\section{Testishistologie bij NOA}

Histologisch kan NOA geclassificeerd worden als sertoli cell only (SCO) syndroom, maturatie arrest (MA) of hypospermatogenese.

\section{Sertoli cell only syndroom}

De definitie van generaliseerd SCO-syndroom is afwezigheid van spermatogene stamcellen en germinale cellen. SCO wordt bijvoorbeeld gezien na oncologische behandeling met gonadotoxische chemotherapie met depletie van germinale cellen, maar komt ook idiopathisch en bij ernstige testiculaire dysgenesie voor. Het klinisch beeld van SCO zijn weke, kleine testes met niet-gedilateerde epididymides. Het endocrinologisch onderzoek toont een verhoogd FSH- en een verlaagd inhibine B-gehalte, wat duidt op verstoorde spermatogenese, en een verlaagd aan- 
tal germinaal epitheel. Bij ongeveer $40 \%$ van de patiënten met SCO in de testishistologie worden bij TESE toch zaadcellen gevonden. Dit is indirect bewijs voor focale spermatogenese, waarbij het histologiebiopt een sampling error vertoont [19]. Het voorkomen van eilandjes met intacte spermatogenese in testes met niet-gegeneraliseerde SCO, verklaart ook waarom FSH en inhibine B geen goede voorspellers zijn van de uitkomst van TESE [20, 21].

\section{Maturatiearrest}

Maturatiearrest wordt gedefinieerd als de afwezigheid van volwassen spermatozoa ten gevolge van een defect in de eerste of tweede kerndeling die spermatocyten ondergaan om te ontwikkelen tot een haploïde zaadcel. Met vroege MA wordt een arrest in de spermatogonia of het spermatocytenstadium bedoeld; late MA vindt plaats in het spermatide stadium. Diffuse MA in $100 \%$ van de tubuli heeft een genetische etiologie, maar komt weinig voor. In een studie van Bernie et al. onder 211 mannen met NOA bij wie MA werd vastgesteld, werd bij $25 \%$ van de patiënten gegeneraliseerde MA gevonden, bij de overige patiënten histologische mengbeelden [22]. De sperm retrieval rate (SRR) bij heterogeen verspreide MA was $35 \%$ ten opzichte van $57 \%$ bij focale MA. Late MA was gunstiger voor de SRR dan vroege MA [22].

FSH correleert met het aantal spermatogonia in de testes. Verhoogd serum-FSH duidt op verminderde germinale activiteit of zelfs afwezigheid van de spermatogonia. Mannen met een normaal FSH, een laag-normaal testisvolume bij wie op basis van voorgeschiedenis, lichamelijk onderzoek en echografie van de testes de verdenking op obstructie laag is, kunnen vroege MA hebben.

\section{Hypospermatogenese}

Bij hypospermatogenese zijn alle germinale celtypen aanwezig, maar is de spermatogenese geheel gereduceerd. Dit type testishistologie correleert het best met positieve SRR. In een studie van Caroppo et al. was de SRR $88 \%$ bij hypospermatogenese, versus $30 \%$ bij SCO [23].

Aangezien testishistologie peroperatief bij de TESE-procedure wordt verkregen, is er geen sprake van een klinischrelevante predictor voor de uitkomt van TESE.

\section{Operatietechniek TESE}

Testiculaire sperma-aspiratie (TESA) is een blinde dan wel echogeleide procedure met een fine-needle biopsie, die poliklinisch onder lokale anesthesie kan worden uitgevoerd. De procedure geeft redelijke resultaten bij OA, maar infe- rieure resultaten bij NOA [24]. TESA wordt in Nederland niet toegepast.

Bij conventionele TESE (cTESE) worden één, drie (trifo$\mathrm{cal}$ ) of multipele biopten van testis parenchym afgenomen. De Amerikaanse uroloog Peter Schlegel introduceerde in 1999 de microdissectie-TESE waarbij de geopende testis onder 20-25 $\times$ vergroting geïnspecteerd wordt en alleen gedilateerde tubuli met een wittig aspect worden weggenomen en aangeboden aan de embryoloog voor zaadcelextractie [25]. Met deze techniek zou de SRR hoger zijn dan bij cTESE en het risico op devascularisatie van de testis, met hypogonadisme tot gevolg, lager zijn.

Sindsdien zijn er geen gerandomiseerde studies verricht om het verschil in SRR bij micro-TESE versus cTESE aan te tonen. Een systematische review uit 2014 onder zeven retrospectieve of pseudogerandomiseerde prospectieve studies toonde aan dat de SRR bij micro-TESE superieur lijkt. De SRR bij cTESE varieerde van 16,7-45\% versus 42,9-63\% bij micro-TESE [25].

Micro-TESE lijkt succesvoller bij SCO in twee studies en bij hypospermatogenese in één studie. Bij MA lijkt micro-TESE geen meerwaarde te hebben boven cTESE [26].

Bewijs dat een van de hiervoor genoemde technieken leidt tot een hogere kans op zwangerschap, ontbreekt. Waarschijnlijk is de belangrijkste factor voor positieve SRR niet de operatietechniek, maar de kwaliteit van de verwerkte TESE-biopten en het volume ervan op het IVFlaboratorium. Publicatiebias ontstaat doordat internationale hoogvolumecentra doorgaans enkel micro-TESE toepassen.

\section{Work-up van TESE}

In de diagnostische work-up van azoöspermie kan op basis van de medische voorgeschiedenis, het lichamelijk onderzoek, laboratoriumonderzoek van gonadotrofinen en scrotale echografie veelal onderscheid gemaakt worden tussen NOA en OA.

OA wordt gekenmerkt door een voorgeschiedenis zonder indalingsstoornis van de testes, orchidopexie, torsio testis of boforchitis. Doorgemaakte epididymitis, prostatitis of soa's kunnen suggestief zijn voor intratesticulaire, epididymale of obstructie van de ductus ejaculatorius. De afwezigheid van het vas deferens wijst op congenitale bilaterale afwezigheid van het vas deferens. Vast-elastische testis, van ten minste $15 \mathrm{cc}$, zonder stuwing van de epididymi correleren met intacte spermatogenese. FSH, inhibine B, LH en testosteron binnen de referentiewaarden zijn suggestief voor intacte spermatogenese. Echografisch onderzoek van het scrotum kan de verdenking op obstructie bevestigen of vaststellen wanneer het testisvolume en parenchym normaal zijn en de tubuli seminiferi in de epididymis zichtbaar zijn. 
Huisartsen en diagnostische laboratoria in algemene ziekenhuizen classificeren het aantal zaadcellen in een ejaculaat vaak niet onder een concentratie van twee of 1 miljoen per milliliter, aangezien de bepaling onbetrouwbaarder wordt vanaf ernstige oligospermie $(<5 \mathrm{M} / \mathrm{ml})$ en cryptozoöspermie $(<1$ miljoen/ml). In gespecialiseerde IVFcentra wordt bij cryptozoöspermie dikke-druppelejaculaatonderzoek gedaan naar zaadcellen die geschikt zijn voor ICSI. Vervolgens wordt bij afwezigheid van zaadcellen het ejaculaat afgedraaid op $3.000 \mathrm{~g}$ gedurende $15 \mathrm{~min}$, waarna de pellet microscopisch wordt onderzocht op zaadcellen. Absolute azoöspermie wordt gediagnosticeerd wanneer ook in het pelletonderzoek geen zaadcellen worden gevonden.

Deze werkwijze, en het feit dat cryptozoöspermie en azoöspermie afwisselend kunnen optreden, zijn verklaringen voor het feit dat mannen die verwezen worden naar gespecialiseerde IVF-centra voor TESE toch voor reguliere ICSI in aanmerking kunnen komen. In onze ervaring is een 'zoek-ICSI' met ejaculatoire zaadcellen toch mogelijk bij een op de vijf mannen die verwezen wordt voor TESE.

Tot slot complementeert genetisch onderzoek de workup van een man met NOA voor TESE.

\section{Mogelijke complicaties en langetermijngevolgen}

Naast algemene complicaties als nabloeding en infectie, is het risico op testisatrofie met secundair hypogonadisme ten gevolge van TESE zeer laag. In een systematische review was de gerapporteerde hematoomvorming, fibrose van het testisparenchym en afname van het echografisch gemeten testisvolume kleiner na micro-TESE in vergelijking tot cTESE [26].

De meta-analyse van een recent uitgevoerde systematische review laat zes maanden na een TESE een passagière, maar statistisch significante afname van testosteronwaarden zien. Bij mannen met NOA was de gemiddelde testosteronafname $2,7 \mathrm{nmol} / 1$. De testosteronwaarden normaliseerden echter weer spontaan 18 maanden na de TESE [27].

Hypogonadisme, uitgedrukt als testosteron $<10 \mathrm{nmol} / 1$ vóór 10 uur's ochtends gemeten, wordt vastgesteld bij ongeveer $20 \%$ van de mannen die voor work-up van TESE de polikliniek bezoeken (eigen praktijk). Veelal is dit hypogonadisme asymptomatisch in de cognitieve domeinen en in de domeinen van het bewegingsapparaat en de vitaliteit. Seksuele disfunctie komt vaak voor bij mannen die gediagnosticeerd worden met azoöspermie, onafhankelijk van de waarde van het testosteron. Erectiele disfunctie, premature ejaculatie en verminderde zin in seks worden significant vaker aangetoond bij mannen met een recente azoöspermiediagnose in vergelijking tot mannen met ongestoorde fertiliteit. Ook de psychologische belasting, angst en algemene gezondheid, uitgedrukt met een chronic disease score, is significant hoger bij mannen met NOA [28].

In een cross-sectionele studie onder 2.100 mannen die fertiliteitsanalyse ondergingen, bleek azoöspermie geassocieerd te zijn met een hogere score op de Charlson Comorbidity Index [29]. Dergelijke studies suggereren dat een NOA-diagnose beschouwd kan worden als een indicator voor algemene gezondheidsrisico's en mogelijkheden biedt om preventieve adviezen te geven op het gebied van leefstijl.

\section{Controversies}

$\mathrm{Er}$ is geen verschil aangetoond in zwangerschapspercentages na TESE-ICSI met vers geoogste testiculaire zaadcellen versus gecryopreserveerde-ontdooide testiculaire zaadcellen [30]. Vanzelfsprekend is de logistiek en planning van de TESE-ICSI-behandeling met vooraf gecryopreserveerde zaadcelen eenvoudiger en het risico op afwezigheid van vitale testiculaire zaadcellen kleiner dan bij een acute, verse TESE. Overigens toonden Schachter-Safrai et al. recent aan dat de uitkomst van ICSI met vooraf gecryopreserveerde ejaculatoire zaadcellen bij cryptozoöspermie wel inferieur is ten op zicht van ICSI met verse cryptozoöspermie [31].

De resultaten van studies die onderzochten of het gebruik van ejaculatoire zaadcellen bij cryptozoöspermie betere ICSI-resultaten geeft dan testiculair geoogste zaadcellen zijn tegenstrijdig. Toch wordt in een meta-analyse van Abhyankar et al. geen voordeel gezien van het gebruik van testiculaire zaadcellen voor ICSI als er ook ejaculatoire zaadcellen beschikbaar zijn [32].

In de praktijk worden ejaculatoire zaadcellen verkozen boven testiculaire zaadcellen. Expert opinion is dan ook dat TESE geen aanvullende waarde heeft voor de uitkomst van ICSI als er enkel afwijkende zaadcellen in het ejaculaat voorkomen. Een recente systematische review en metaanalyse concludeert echter dat TESE-ICSI betere uitkomst zou hebben dan conventionele ICSI bij mannen met een hoge mate van zaadcel-DNA-fragmentatie in het ejaculaat [33].

Er zijn aanwijzingen dat het corrigeren van een klinische varicocele bij NOA de kans op positieve sperm retrieval bij TESE verhoogt met 2,6 keer. De kans op zwangerschap na TESE-ICSI is significant groter als de varicocele voorafgaand aan de TESE werd gecorrigeerd [34]. Deze resultaten zijn suggestief voor een positief effect van varicocelectomie in de context van TESE, maar moeten terughoudend geïnterpreteerd worden, aangezien het kleine, niet-gerandomiseerde studies betreft. 


\section{Innovatie van diagnostiek en behandeling}

TESE en TESE-ICSI leidden tot een enorme verbetering in de behandelopties voor kinderwens bij mannen met NOA. Helaas zijn de procedures inefficiënt doordat voorspellers voor het vinden van zaadcellen bij TESE ontbreken. De behandeling slaagt niet altijd. Er moet een grote tijdsinvestering geleverd worden in de laboratoriumfase, zowel voor de verwerking van het testiculaire weefsel en de zaadcelextractie, als voor het selecteren van de geschikte testiculaire zaadcellen voor injectie van de oöcyten. Bespreking van de kansen op een kind hebben in de praktijk weinig invloed op de keuze van patiënten voor TESE dan wel het alternatief, zaadceldonatie. Tegen de achtergrond van de emotionele belasting van de confrontatie met ongewenste kinderloosheid of niet-biologisch vaderschap, opteert het merendeel van de patiënten voor TESE, ook als de a-priorikans op een kind laag is. Feitelijk is behandeling met zaadceldonatie veiliger, effectiever en goedkoper.

De behandeling is slechts in beperkte mate doeltreffend omdat robuuste diagnostiek voor de selectie van patiënten met positieve sperm retrieval ontbreekt, er geen uniforme definitie bestaat voor succesvolle TESE en kosteneffectiviteitsanalyses van de TESE-ICSI-uitkomst ontbreken.

$\mathrm{Er}$ is innovatie te verwachten op het gebied van moleculaire markers in het ejaculaat, die de aanwezigheid van spermatogenese kunnen voorspellen. Daarnaast is imaging op cellulair of zelfs nucleair niveau van het testisparenchym en de zaadcel in ontwikkeling met als doel de operatietijd te verkorten, en zal leiden tot een grotere kans op het aanleveren van weefsel of tubuli waarin zaadcellen gevonden gaan worden. Microfluidics en Raman-spectroscopy van de individuele zaadcel zijn veelbelovende innovatieve technieken waarmee de selectie van zaadcellen met maximaal bevruchtend vermogen geselecteerd kunnen worden [35].

Open Access This article is distributed under the terms of the Creative Commons Attribution 4.0 International License (http:// creativecommons.org/licenses/by/4.0/), which permits unrestricted use, distribution, and reproduction in any medium, provided you give appropriate credit to the original author(s) and the source, provide a link to the Creative Commons license, and indicate if changes were made.

\section{Literatuur}

1. Jarow JP, Espeland MA, Lipshultz LI. Evaluation of the azoospermic patient. J Urol. 1989;142(1):62-5.

2. Marmar JL. Modified vasoepididymostomy with simultaneous double needle placement, tubulotomy and tubular invagination. J Urol. 2000;163(2):483-6.

3. Verheyen G, Popovic-Todorovic B, Tournaye H. Processing and selection of surgically-retrieved sperm for ICSI: a review. Basic Clin Androl. 2017;27:6.

4. Krausz C. Male infertility: pathogenesis and clinical diagnosis. Best Pract Res Clin Endocrinol Metab. 2011;25(2):271-85.
5. Craft I, Bennett V, Nicholson N. Fertilising ability of testicular spermatozoa. Lancet. 1993;342(8875):864.

6. Devroey P, Liu J, Nagy Z, Tournaye H, Silber SJ, Van Steirteghem AC. Normal fertilization of human oocytes after testicular sperm extraction and intracytoplasmic sperm injection. Fertil Steril. 1994;62(3):639-41.

7. Woldringh GH, Besselink DE, Tillema AH, Hendriks JC, Kremer JA. Karyotyping, congenital anomalies and follow-up of children after intracytoplasmic sperm injection with non-ejaculated sperm: a systematic review. Hum Reprod Update. 2010;16(1):12-9.

8. Nederlandse Vereniging voor Obstetrie en Gynaecologie. Geassisteerde voortplanting met chirurgisch verkregen zaadcellen. Utrecht: NVOG; 2013.

9. Ghanem M, Bakr NI, Elgayaar MA, El Mongy S, Fathy H, Ibrahim AH. Comparison of the outcome of intracytoplasmic sperm injection in obstructive and non-obstructive azoospermia in the first cycle: a report of case series and meta-analysis. Int $\mathbf{J}$ Androl. 2005;28(1):16-21.

10. Vloeberghs V, Verheyen G, Haentjens P, Goossens A, Polyzos NP, Tournaye H. How successful is TESE-ICSI in couples with nonobstructive azoospermia? Hum Reprod. 2015;30(8):1790-6.

11. Cissen M, Meijerink AM, D'Hauwers KW, Meissner A, Weide N van der, Mochtar MH, et al. Prediction model for obtaining spermatozoa with testicular sperm extraction in men with non-obstructive azoospermia. Hum Reprod. 2016;31(9):1934-41.

12. Vernaeve V, Tournaye H, Osmanagaoglu K, Verheyen G, Van Steirteghem A, Devroey P. Intracytoplasmic sperm injection with testicular spermatozoa is less successful in men with nonobstructive azoospermia than in men with obstructive azoospermia. Fertil Steril. 2003;79(3):529-33.

13. Hessel M, Robben JC, D'Hauwers KW, Braat DD, Ramos L. The influence of sperm motility and cryopreservation on the treatment outcome after intracytoplasmic sperm injection following testicular sperm extraction. Acta Obstet Gynecol Scand. 2015;94(12):1313-21.

14. Wohlfahrt-Veje C, Main KM, Skakkebaek NE. Testicular dysgenesis syndrome: foetal origin of adult reproductive problems. Clin Endocrinol (Oxf). 2009;71(4):459-65.

15. Brakel J van, Kranse R, Muinck Keizer-Schrama SM de, Hendriks AE, Jong FH de, Hack WW, et al. Fertility potential in a cohort of 65 men with previously acquired undescended testes. J Pediatr Surg. 2014;49(4):599-605.

16. D'Hauwers KW. Klinefelter en fertiliteit. Tijdschr Urol. 2018; in press.

17. Hopps CV, Mielnik A, Goldstein M, Palermo GD, Rosenwaks Z, Schlegel PN. Detection of sperm in men with Y chromosome microdeletions of the $\mathrm{AZFa}, \mathrm{AZFb}$ and $\mathrm{AZFc}$ regions. Hum Reprod. 2003;18(8):1660-5.

18. Johnson M, Raheem A, Luca F de, Hallerstrom M, Zainal Y, Poselay S, et al. An analysis of the frequency of Y-chromosome microdeletions and the determination of a threshold sperm concentration for genetic testing in infertilie men. BJU Int. 2018. Epub ahead of print.

19. Abdel Raheem A, Garaffa G, Rushwan N, Luca F de, Zacharakis E, Abdel Raheem T, et al. Testicular histopathology as a predictor of a positive sperm retrieval in men with non-obstructive azoospermia. BJU Int. 2013;111(3):492-9.

20. Yang Q, Huang YP, Wang HX, Hu K, Wang YX, Huang YR, et al. Follicle-stimulating hormone as a predictor for sperm retrieval rate in patients with nonobstructive azoospermia: a systematic review and meta-analysis. Asian J Androl. 2015;17(2):281-4.

21. Goulis DG, Tsametis C, Iliadou PK, Polychronou P, Kantartzi PD, Tarlatzis BC, et al. Serum inhibin B and anti-Mullerian hormone are not superior to follicle-stimulating hormone as predictors of the presence of sperm in testicular fine-needle aspiration in men with azoospermia. Fertil Steril. 2009;91(4):1279-84. 
22. Bernie AM, Shah K, Halpern JA, Scovell J, Ramasamy R, Robinson $\mathrm{B}$, et al. Outcomes of microdissection testicular sperm extraction in men with nonobstructive azoospermia due to maturation arrest. Fertil Steril. 2015;104(3):569-573 e1.

23. Caroppo E, Colpi EM, Gazzano G, Vaccalluzzo L, Scroppo FI, D'Amato G, et al. Testicular histology may predict the successful sperm retrieval in patients with non-obstructive azoospermia undergoing conventional TESE: a diagnostic accuracy study. J Assist Reprod Genet. 2017;34(1):149-54.

24. Jensen CF, Ohl DA, Hiner MR, Fode M, Shah T, Smith GD, et al. Multiple needle-pass percutaneous testicular sperm aspiration as first-line treatment in azoospermic men. Andrology. 2016;4(2):257-62.

25. Schlegel PN. Testicular sperm extraction: microdissection improves sperm yield with minimal tissue excision. Hum Reprod. 1999;14(1):131-5.

26. Deruyver Y, Vanderschueren D, Aa F van der. Outcome of microdissection TESE compared with conventional TESE in non-obstructive azoospermia: a systematic review. Andrology. 2014;2(1):20-4.

27. Eliveld J, Wely $M$ van, Meissner A, Repping S, Veen $F$ van der, Pelt AMM van. The risk of TESE-induced hypogonadism: a systematic review and meta-analysis. Hum Reprod Update. 2018;24(4):442-54.

28. Lotti F, Corona G, Castellini G, Maseroli E, Fino MG, Cozzolino $\mathrm{M}$, et al. Semen quality impairment is associated with sexual dysfunction according to its severity. Hum Reprod. 2016;31(12): 2668-80.

29. Ventimiglia E, Capogrosso P, Boeri L, Serino A, Colicchia M, Ippolito $\mathrm{S}$, et al. Infertility as a proxy of general male health: results of a cross-sectional survey. Fertil Steril. 2015;104(1):48-55.
30. Ben-Yosef D, Yogev L, Hauser R, Yavetz H, Azem F, Yovel I, et al. Testicular sperm retrieval and cryopreservation prior to initiating ovarian stimulation as the first line approach in patients with nonobstructive azoospermia. Hum Reprod. 1999;14(7):1794-801.

31. Schachter-Safrai N, Karavani G, Levitas E, Friger M, Zeadna A, Lunenfeld E, et al. Does cryopreservation of sperm affect fertilization in nonobstructive azoospermia or cryptozoospermia? Fertil Steril. 2017;107(5):1148-52.

32. Abhyankar N, Kathrins M, Niederberger C. Use of testicular versus ejaculated sperm for intracytoplasmic sperm injection among men with cryptozoospermia: a meta-analysis. Fertil Steril. 2016;105(6):1469-1475e1.

33. Esteves SC, Roque M, Bradley CK, Garrido N. Reproductive outcomes of testicular versus ejaculated sperm for intracytoplasmic sperm injection among men with high levels of DNA fragmentation in semen: systematic review and meta-analysis. Fertil Steril. 2017;108(3):456-67e1.

34. Esteves SC, Miyaoka R, Roque M, Agarwal A. Outcome of varicocele repair in men with nonobstructive azoospermia: systematic review and meta-analysis. Asian J Androl. 2016;18(2):246-53.

35. Samuel R, Badamjav O, Murphy KE, Patel DP, Son J, Gale BK, et al. Microfluidics: the future of microdissection TESE? Syst Biol Reprod Med. 2016;62(3):161-70.

Marij Dinkelman-Smit EAA-gecertificeerd klinisch androloog 